\title{
Interdisciplinary Approach: Role of Orthodontist in Management of Impaction; an Evidence Based Study.
}

\author{
Dr.Renuka Patel ${ }^{1}$, Dr.FalguniMehta ${ }^{2}$, Dr. Vijay Vaghela ${ }^{3}$ \\ ${ }^{I}$ (Assistant professor, Dept.of orthodontics, Govt.dental College and hospital, Ahmedabad, Gujarat, India) \\ ${ }^{2}$ (Professor and head, Dept.of orthodontics, Govt.dental College and hospital, Ahmedabad, Gujarat, India) \\ ${ }^{3}$ (PG part-III., Dept.of orthodontics, Govt.dental College and hospital, Ahmedabad, Gujarat, India)
}

\begin{abstract}
Management of impacted teeth in the orthodontic practice is of paramount importance, as the existence of one or more impacted teeth may complicate orthodontic treatment and present dilemmas especially when inaccessibility or ankylosis is factor. The management of impacted teeth in orthodontic practice varies widely from extraction of the tooth to forced orthodontic eruption. Orthodontic eruption varies between closed or open techniques that must be determined for each case.
\end{abstract}

Key Words: impacted teeth, orthodontic treatment, surgical exposure, smile makeover.

\section{Introduction}

The term impaction is of Latin origin coming from the term "impactus" whichmeans "wedged or packed in together".

Impacted tooth is defined as tooth whose roots are $2 / 3$ rd or fully developed but nevertheless expected to erupt.

In impacted teeth, root development might have finished, but unaided eruption is not expected to occur. Occasionally, malposition of a permanent tooth bud can lead to eruption at a wrong place.

Archer observed impacted teeth occurring in the following order of frequency; Maxillary third molars $>$ Mandibular third molars $>$ Maxillary cuspids $>$ Mandibular bicuspids $>$ Mandibular cuspids $>$ Maxillary bicuspids $>$ Maxillary central incisors $>$ Maxillary lateral incisors.

In maxillary canine impaction, palatal canine impaction is more common than buccal canine impaction. \{Jacoby 3:1\}.Females affected more than males. Oliver 1989 showed Asians affected from buccally impacted canines more frequently than from palatally impacted canines.

According to Moyers Concept the factors leading to impaction are : Trauma to deciduous tooth bud, Rate of Resorption of deciduous tooth, Availability of space in the arch, Disturbance in tooth Eruption Sequence, Rotation of tooth buds, Canine impaction in Cleft area in Person with Cleft, Premature root Closure , Abnormal muscle pressure and systemic conditions like Malnutrition, Tuberculosis, Syphilis, Rickets, Anemia,

Progeria and syndromes such as Cleidocranial dysplasia, Achondraplasia, Down syndrome etc .

The treatment of impacted teeth other than third molars has been a grey area in the field of esthetic dentistry since long. Previous practitioners often avoid the management through the eruption technique as it is cumbersome and requires more time. But considering the golden principal of conservation of natural teeth to the maximum and avoidance of future pathologies relating to the untreated impacted teethsuch as root resorption of adjacent teeth, migration of neighboring teeth, loss of arch length ,crowding, spacing, Internal resorption of impacted tooth ,Dentigerous cyst formation, Ankylosis and periodontal pockets etc.

It is suggestive that if possible the teeth should be brought to the occlusal table and assimilated in the natural dental arch to relieve psychological stress, to provide esthetically pleasant smile, to prevent the prosthetic replacement and complications related to untreated impacted teeth.

\section{Investigation}

Special radiographs required to detect impaction,includes

- Iopa:

It shows root development, pattern and integrity, amount of overlying bone, periodontal ligament space and angulation of tooth.

- Tube Shift Technique (Parallax Method):

Where two periapical views of same object are taken at different angles will depict the position of tooth in buccolingual position. 
- True Occlusal Or Vertex Occlusal :

In this view the anteriors are seen as small tiny concentric circles. If the impacted tooth is not parallel to neighbouring tooth, depending on angulation of long axis of the tooth it will be elliptical or oblique in cross section. If tooth is horizontal its full length will be seen.

\section{- Opg:}

It enables viewing of both maxillary and mandibular arhes with their supporting structures. Thus, a single image covers a major part of the facial region. They can be used to view ankylosed, impacted and supernumerary teeth in relation to other facial structures.

\section{- PosteroAnterior view :}

This represents the vertical position of the tooth, the buccolingual tilt of the tooth is also clearly visible. This view also shows whether the root apex is in line of arch and how far the crown is deflected in palatal direction.

In some selective cases to quantify the position of impacted tooth, a 3D image like CT should be used. In which serial radiograph slices of the jaw, the relationship of the impacted tooth to adjacent teeth in all the three plane of space can be accurately assessed, but not indicated in routine due to high radiation dose and cost.

\section{III.Treatment Options} for the tooth

During 1950s orthodontist themselves reffered patients to oral surgeons and they decide the treatment

They provide optimal enviroment for normal and unhinder eruption of the impacted tooth. If the tooth is very deep, extracting the tooth and prosthesis.

In 1968 Moss showed Reimplantion of canine in its position after extracting deciduous canine.

In 1971 Johnston and Lewis showed surgical uncovering of maxillary canine allowing then to eruption spontaneously to a certain degree, followed by buccal traction by means of edge wise appliance.

In 1975 VnderHeydtsurgical uncovering of maxillary canine allowing then to erupt spontaneously to a certain degree followed by later application of Begg's technique.

In 1979 Becker andZibermanpalatal traction applied from TPA or lingual arch.

In 1980 Aitman and Spector showed in cases with difficulty in bringing canine to occlusion, extractthe tooth and substitute by premolar.

After 1980,Treatment plan was done according to the type and level of impaction.

\section{Clinical case series}

This article represents management of different impacted teeth with different treatment modalites; based on type, angulation, favourable- unfavourable position of impacted teeth, availability of space in the arch to achieve good occlusion to improve functional efficiency, to provide esthetically pleasant smile and also to relieve psychological stress related to impacted tooth. Care is taken to find out that impacted tooth is not ankylosed. No positive history of systemic diseases associated with impaction. In all cases surgical exposure is done with different methods followed by orthodontic eruption with closed technique by means of Begg's appliance. Because of vertical gingival facing slot in modified ribbon arch bracket it is easier to ligate the impacted tooth with base arch wire, no in built tip, torque \& rotation in the brackets helps to prevent anchor loss \& space encroachment.

\section{- CASE 1: ' Unilateral Impacted central incisor with multiple supernumerary teeth'}

A male, 15 years old patient reported with the chief complaint of spacing in upper front region. No positive medical or dental history was present.

Radiographic findings revealed impactedmesioangular upper right central incisor on palatal side and multiple fused supernumerary teeth in the mid-line,compositeodontomebetween lower right premolars with skeletal class-I base with normal overjet and overbite, average growth pattern and straight profile. (Fig. 1.1)

Treatment plan was decided toextract impacted composite odontome and multiple fused supernumerary teeth. Surgical exposure of impacted central incisor by tunnel traction technique was done and Begg's bracket bonded on labial surface which is ligated to 0.016 round NiTi. 0.016 special base arch wire with occlusal stop on right canine and left central incisor was pinned up. Once the incisal edge is visible, passiveuprighting spring of 0.016 special is pinned up on left central incisor and right canine, Orthodontic eruption is continued with 0.009 ligature wire, after active treatment time of 18 months, central incisor has been brought to the occlusal table. (Fig. 1.3) 


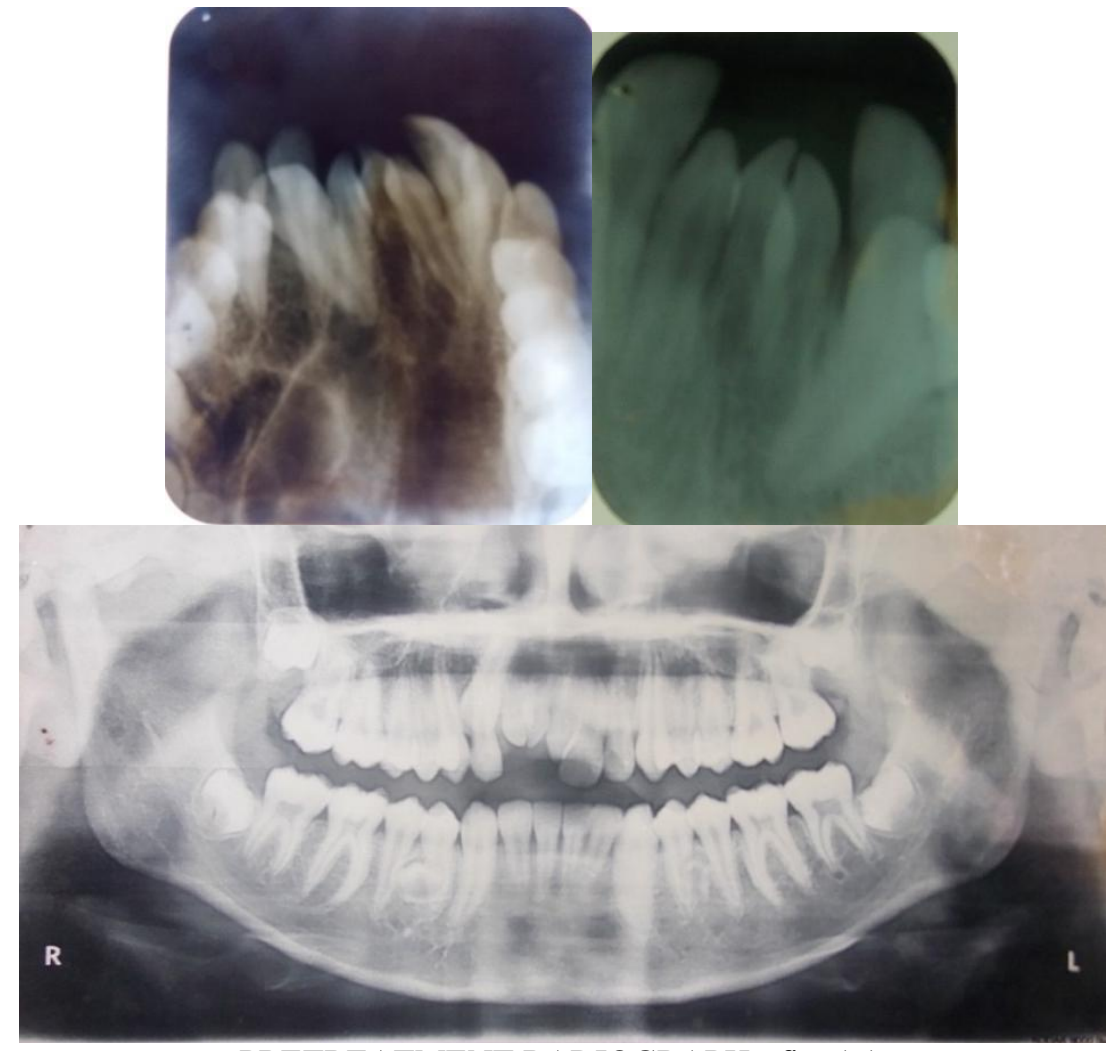

PRETREATMENT RADIOGRAPH - fig. 1.1
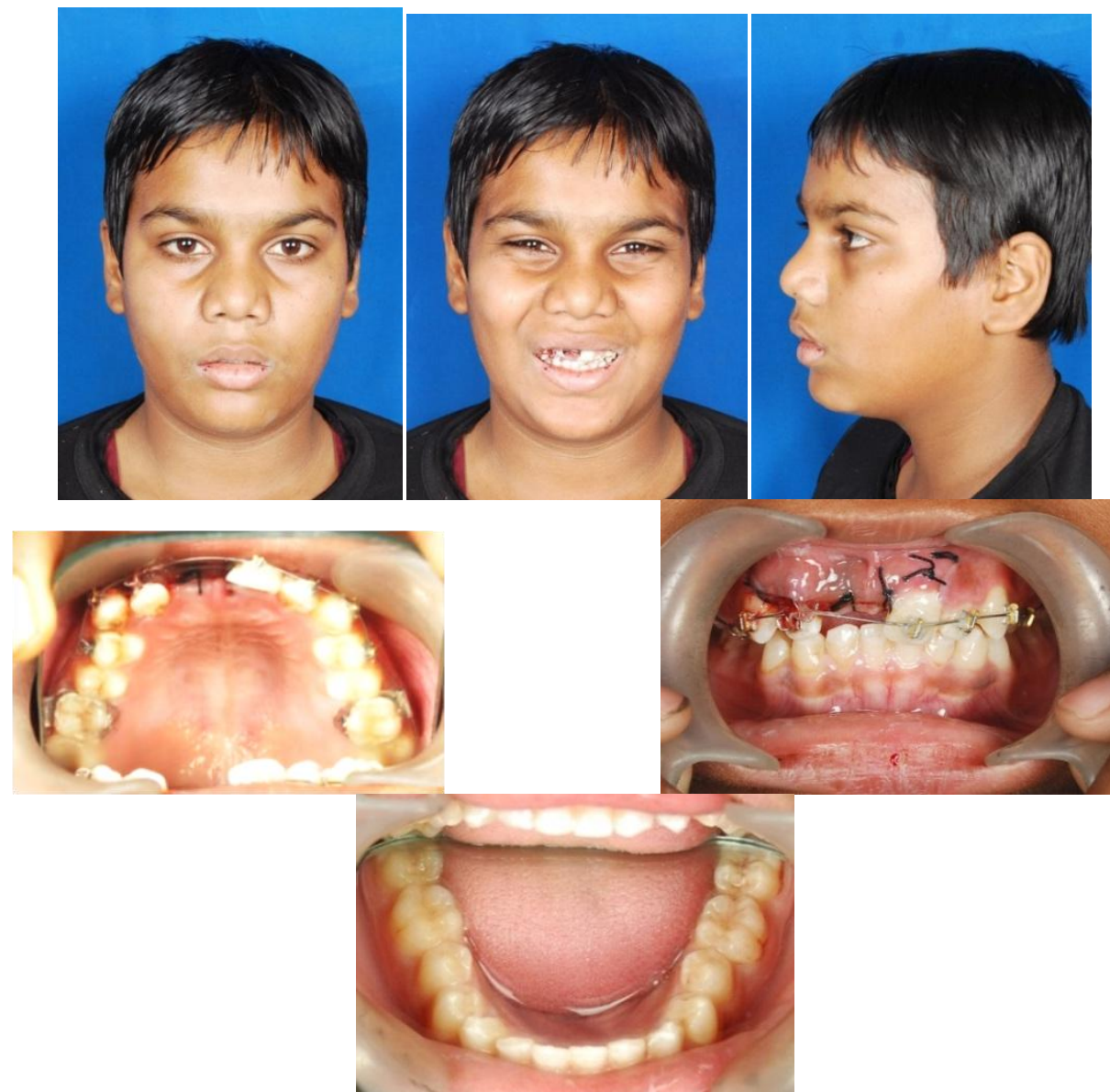

AFTER SURGICAL EXPOSURE - fig 1.2 


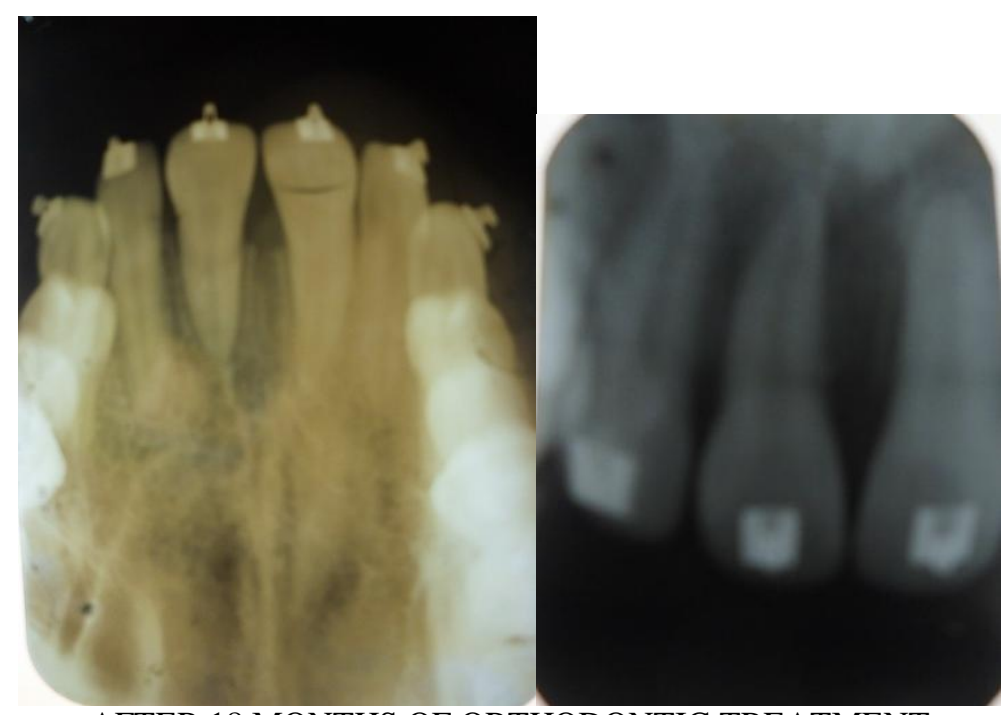

AFTER 18 MONTHS OF ORTHODONTIC TREATMENT

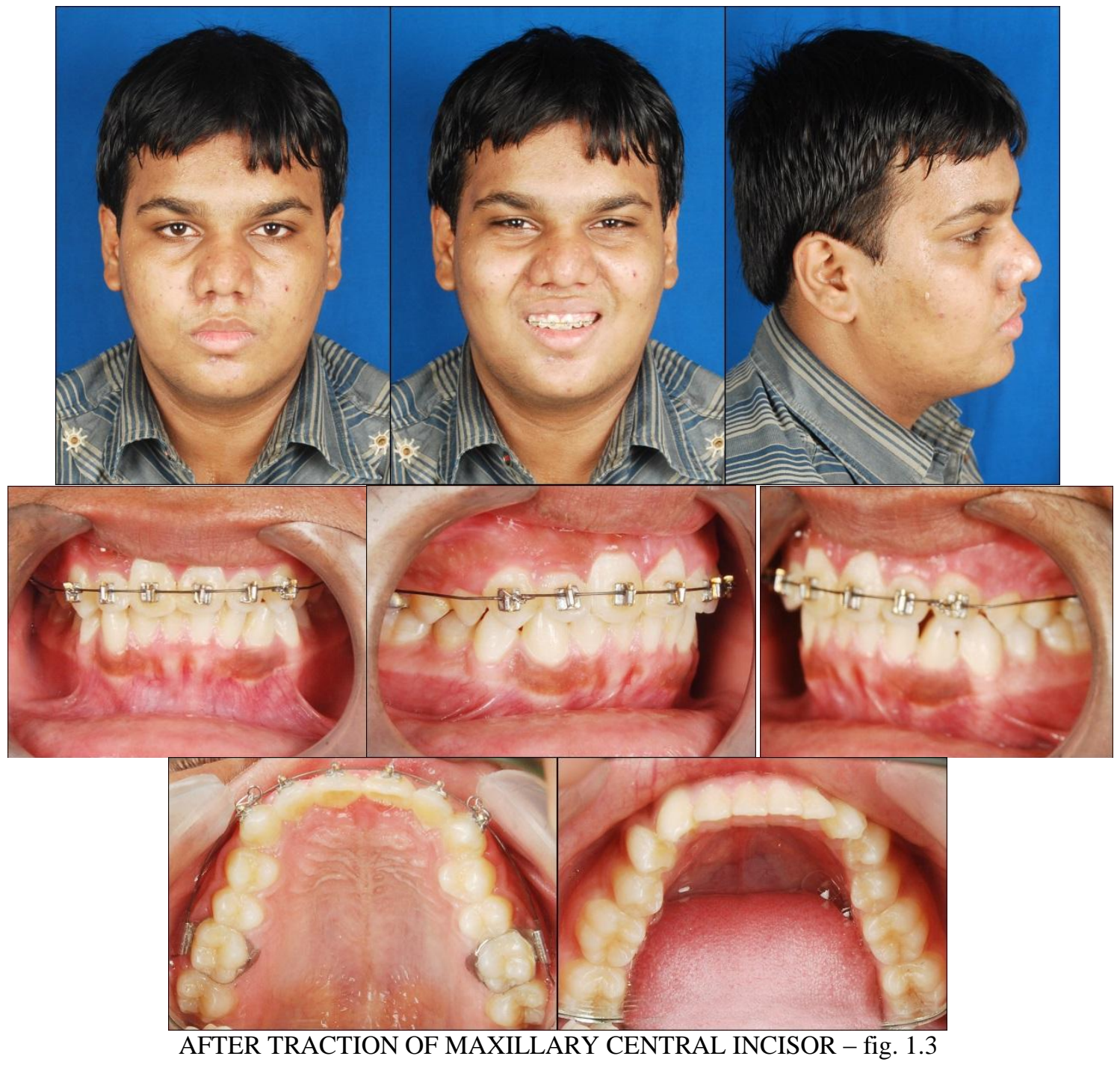


- CASE 2: 'Bilateral impacted maxillary canine with mesiodense'

A male, 12 years old patient reported with chief complain of unevenly arranged front teeth. On examination the findings revealed eruptedmesiodense, bilateral impacted maxillary canine on palatal side , spacing distal to left lateral incisor, anterior deep bite of $7 \mathrm{~mm}$, overjet of $9 \mathrm{~mm}$, distopalatal rotation of upper right central incisor with Angle's class II - subdivison malocclusion with average growth pattern,convex soft tissue profile and lip incompetence.(Fig 2.1 and Fig 2.2)

Treatment plan was decided to extract the mesiodense and utilize the space for overjet reduction by approximating central incisors after derotation of upper right central incisor with 0.016 special closing loop arch wire along with short inter maxillary circle and class II check elastic force.

After 8 months surgical exposure with full thickness periosteal flap of upper left canine for forced orthodontic eruption was doneand Begg's bracket bonded on labial surface and ligated to 0.016 plain NiTi with piggy back technique. After active treatment duration of 22 months upper left canine has been brought to occlusion. After active treatment of 24 months extraction of upper right impacted canine was planned due to lack of space and unfavourableposition near the nasal floor(Fig 2.1.2)

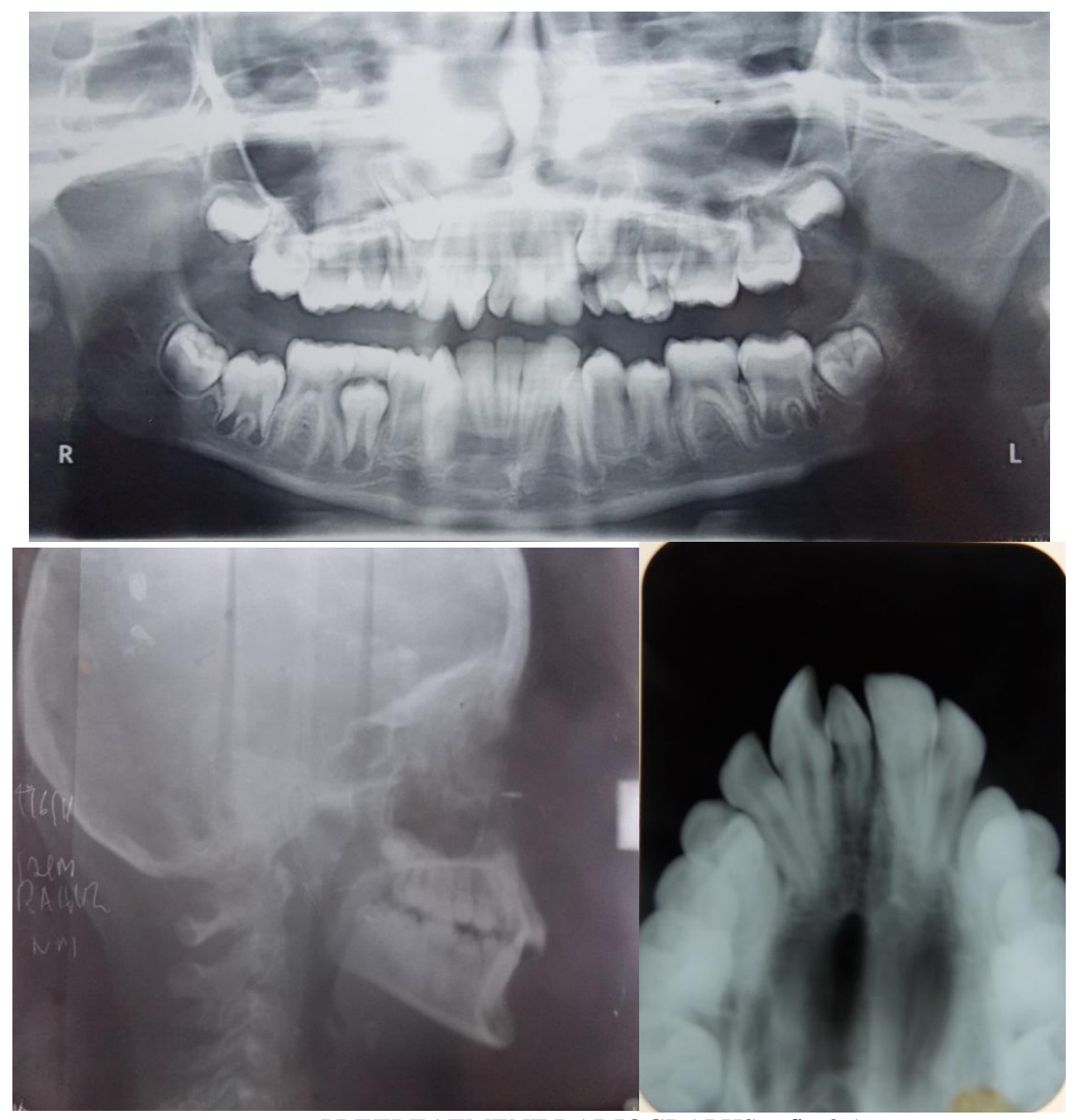

PRETREATMENT RADIOGRAPHS - fig 2.1 


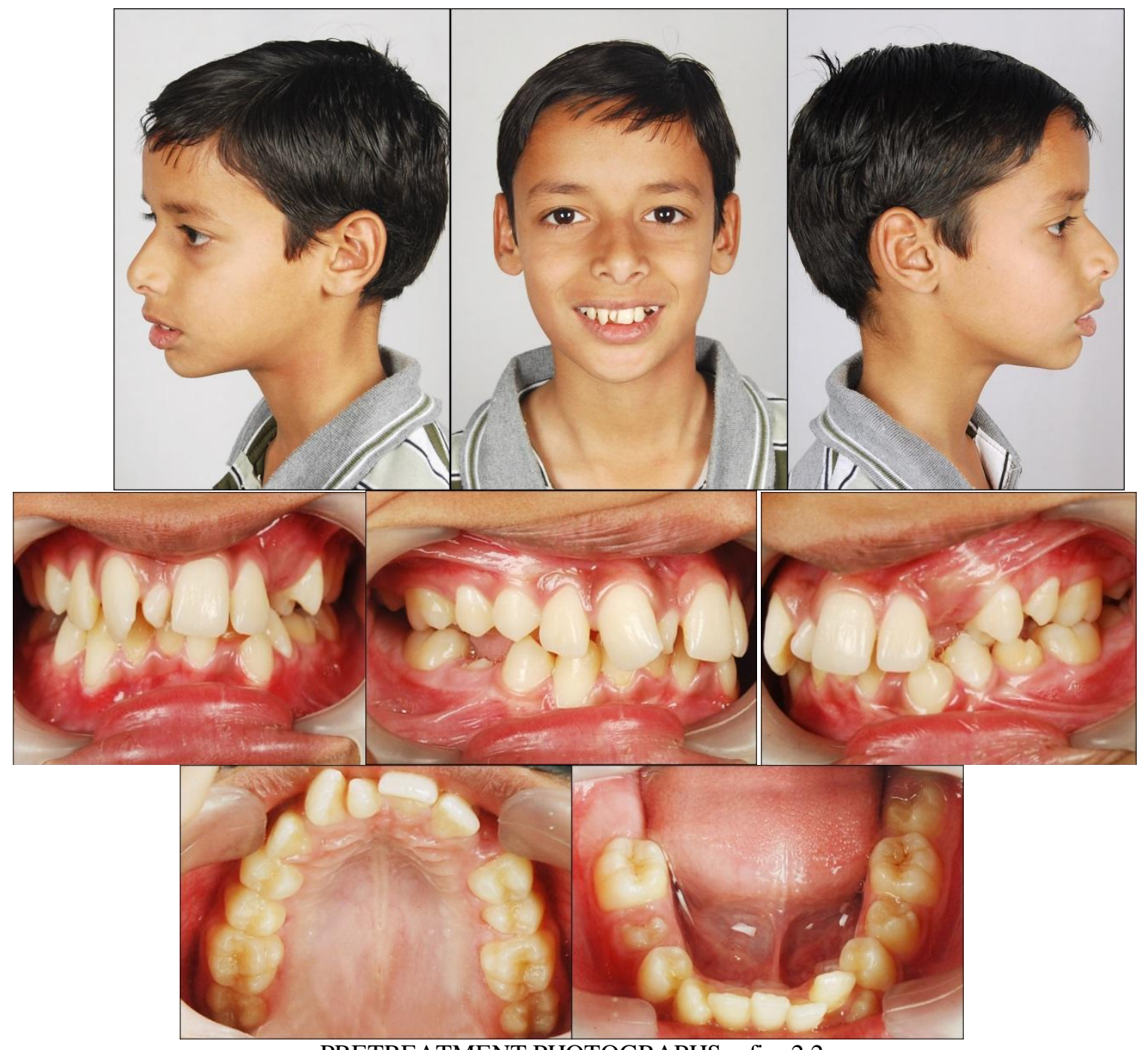

PRETREATMENT PHOTOGRAPHS - fig. 2.2

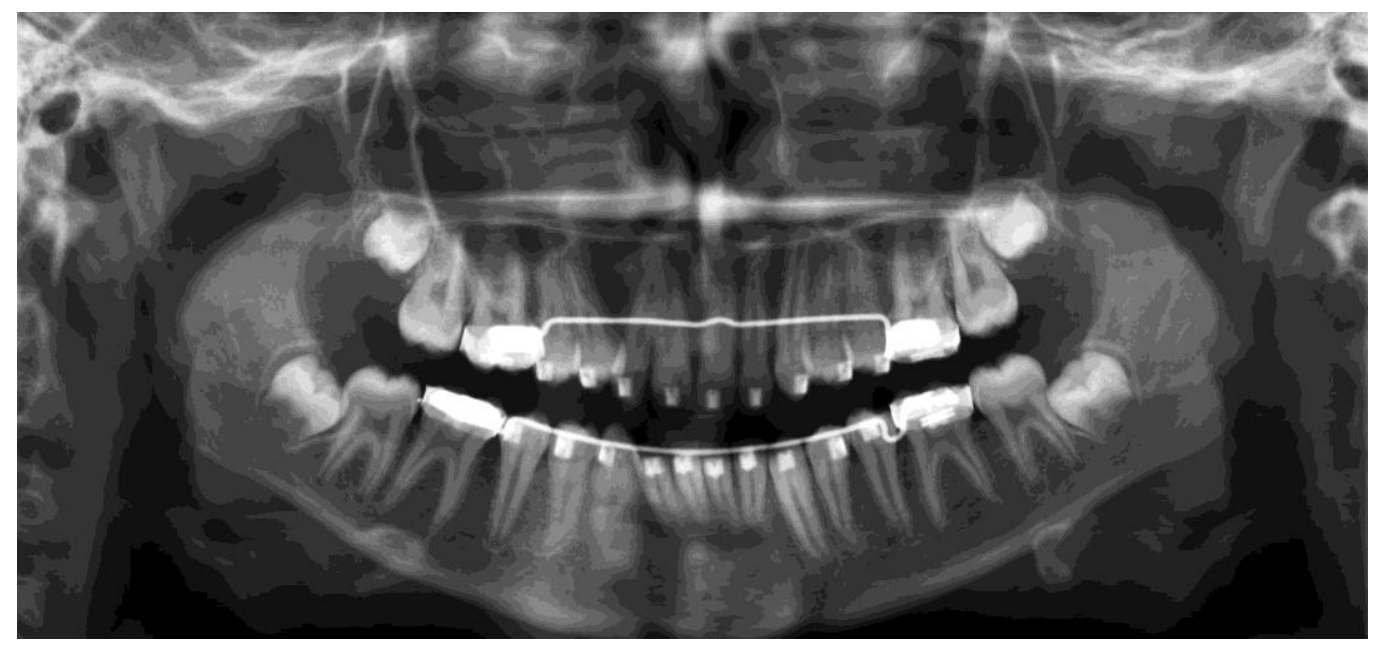

AFTER 24 MONTHS OF TREATMENT-fig 2.1.1 


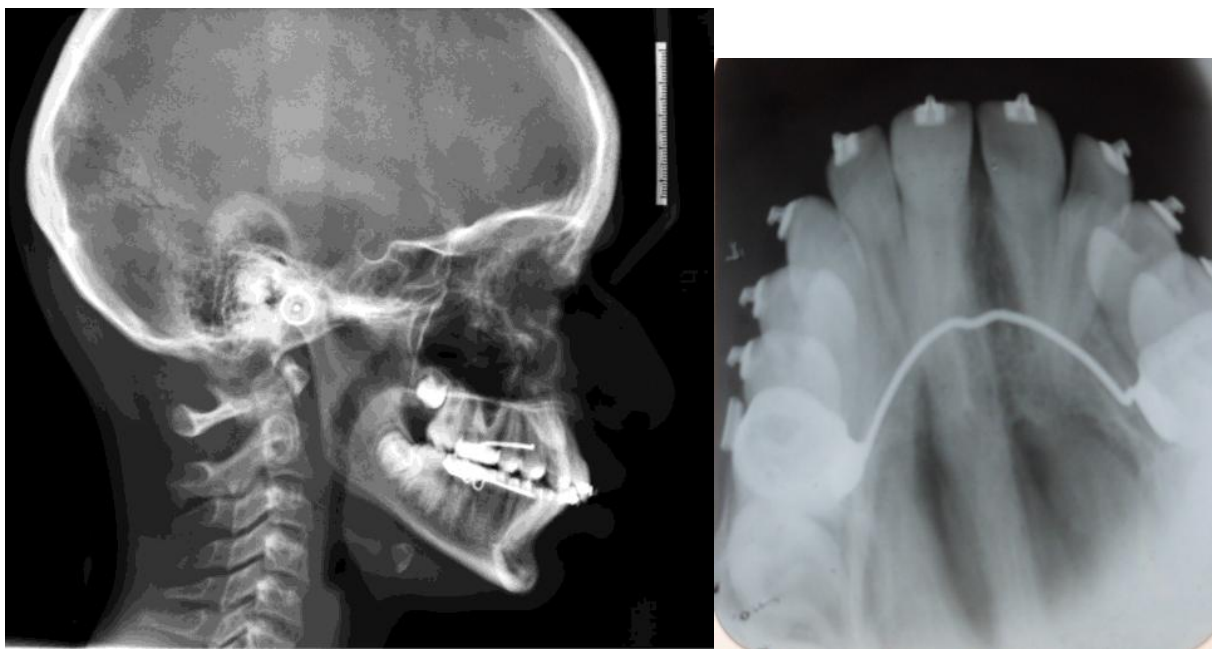

AFTER EXTRACTION OF RIGHT CANINE - fig. 2.1.1

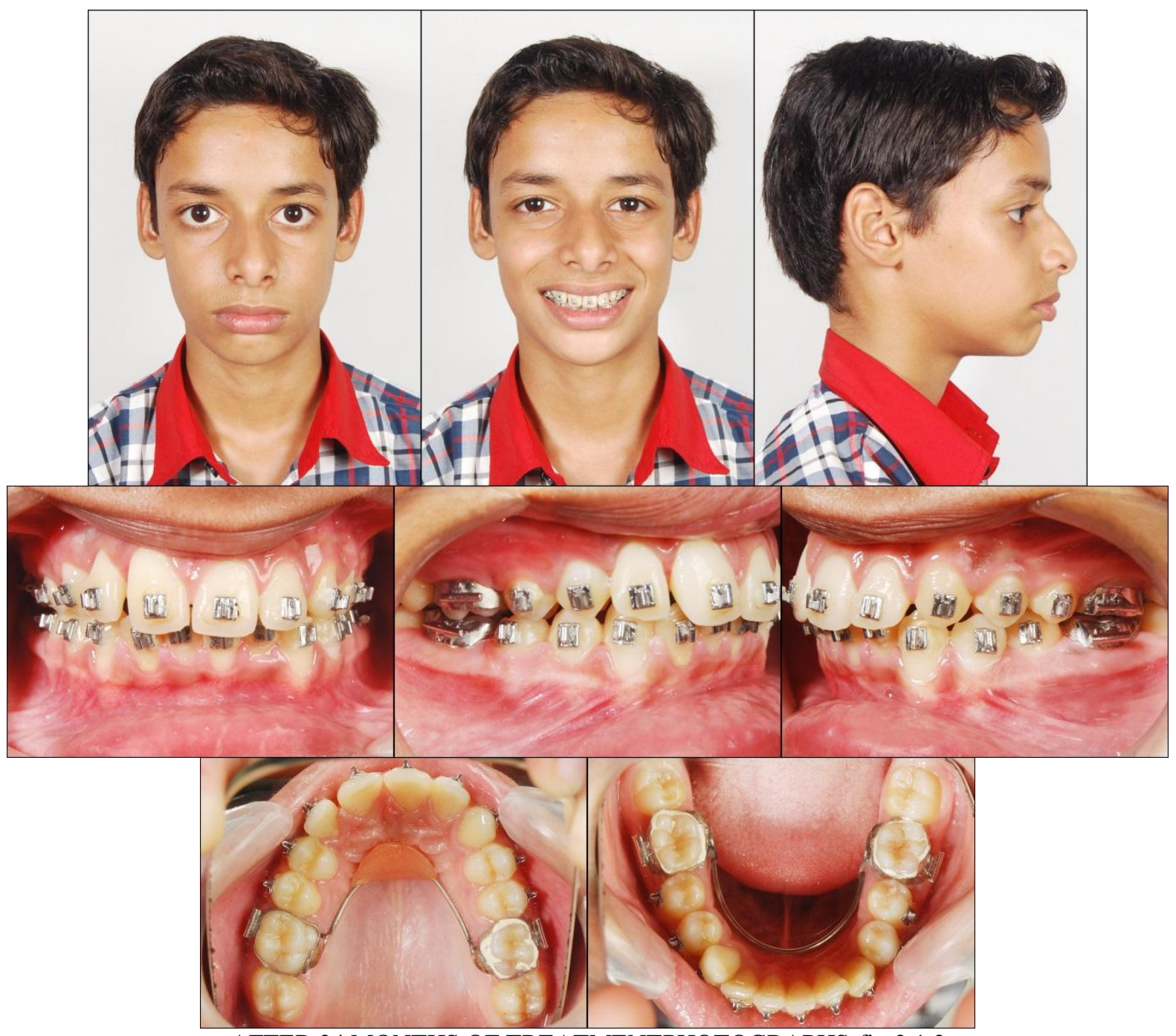

AFTER 24 MONTHS OF TREATMENTPHOTOGRAPHS-fig 2.1.2

- CASE 3: 'Multiple impacted teeth with over retained deciduous canine and molars'

A female 14 years old patient reported with the chief complain of irregularly arranged teeth. On examination the findings revealed overretained deciduous lower right and left lateral incisor, all canine, first and second molars, multiple impactedpermanant teeth including bilateral maxillary and mandibular canines, lower 
left first premolar, lower right lateral incisor, Angle's class-I malocclusion with anterior deep bite and average growth pattern.(fig. 3.1)

First phase treatment was decided to extract overretaineddecioduous teethand patient was kept under observation for 18 months to allow the teeth to erupt on its own but no improvement was observed in canine position, so the orthodontic treatment was started with surgical exposure.

Second phase treatment involves surgical exposure of both maxillary canines by full thickness periosteal flap techniqueand begg's bracket bonded on labial surface, which is ligated to 0.016 round $\mathrm{NiTi}$, 0.016 special plus base arch wire is pinned with passive uprighting springs on lateral incisor and first premolars of both the sides. Removable anterior bite plate was given to relieve deep bite. After 14 months, full thickness periosteal flap technique was planned for surgical exposure of lower left first premolar, right canine and lateral incisor and bracket bonded to labial surface, ligated to 0.016 round NiTi with 0.016 base arch wire with occlusal stops. Extraction of lower left canine was planned because of lack of space in the arch and rotation of tooth make it impossible to bring it orthodontically, after 38 months of active treatment time pleasant smile with class- 1 occlussion is achieved. (fig. 3.1.1)

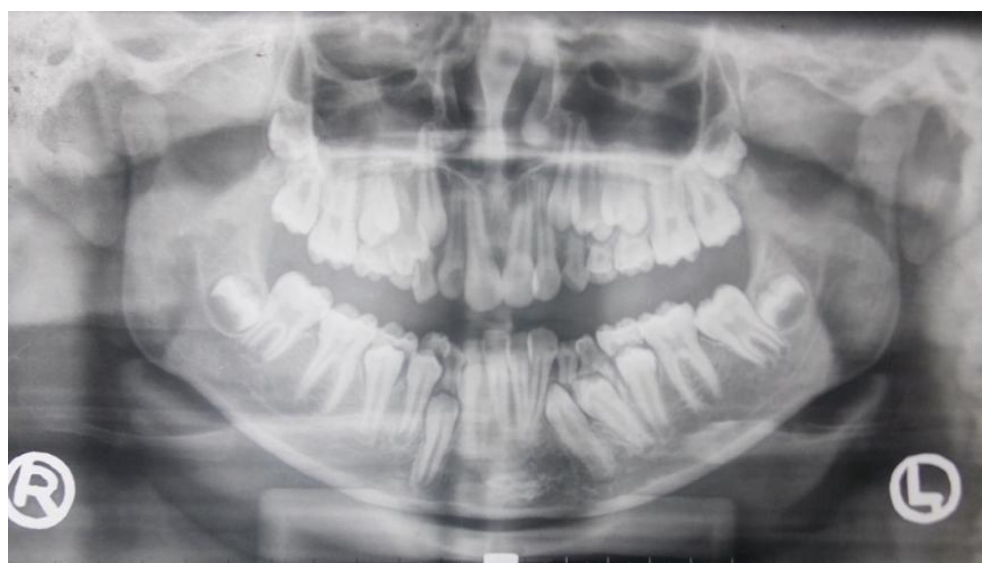

PRETREATMENT OPG - fig. 3.1

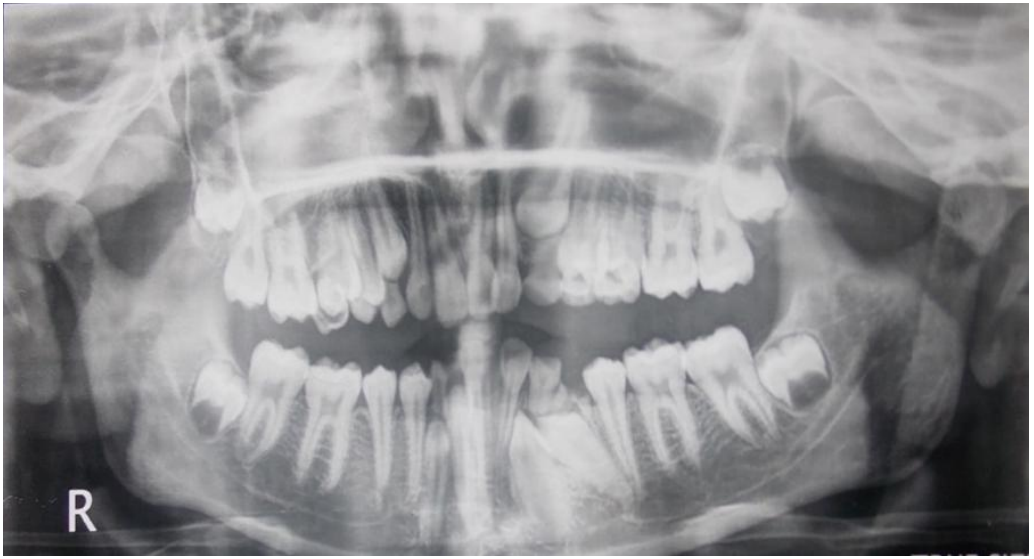

PRETREATMENT OPG BEFORE SURGICAL EXPOSURE - fig. 3.2 


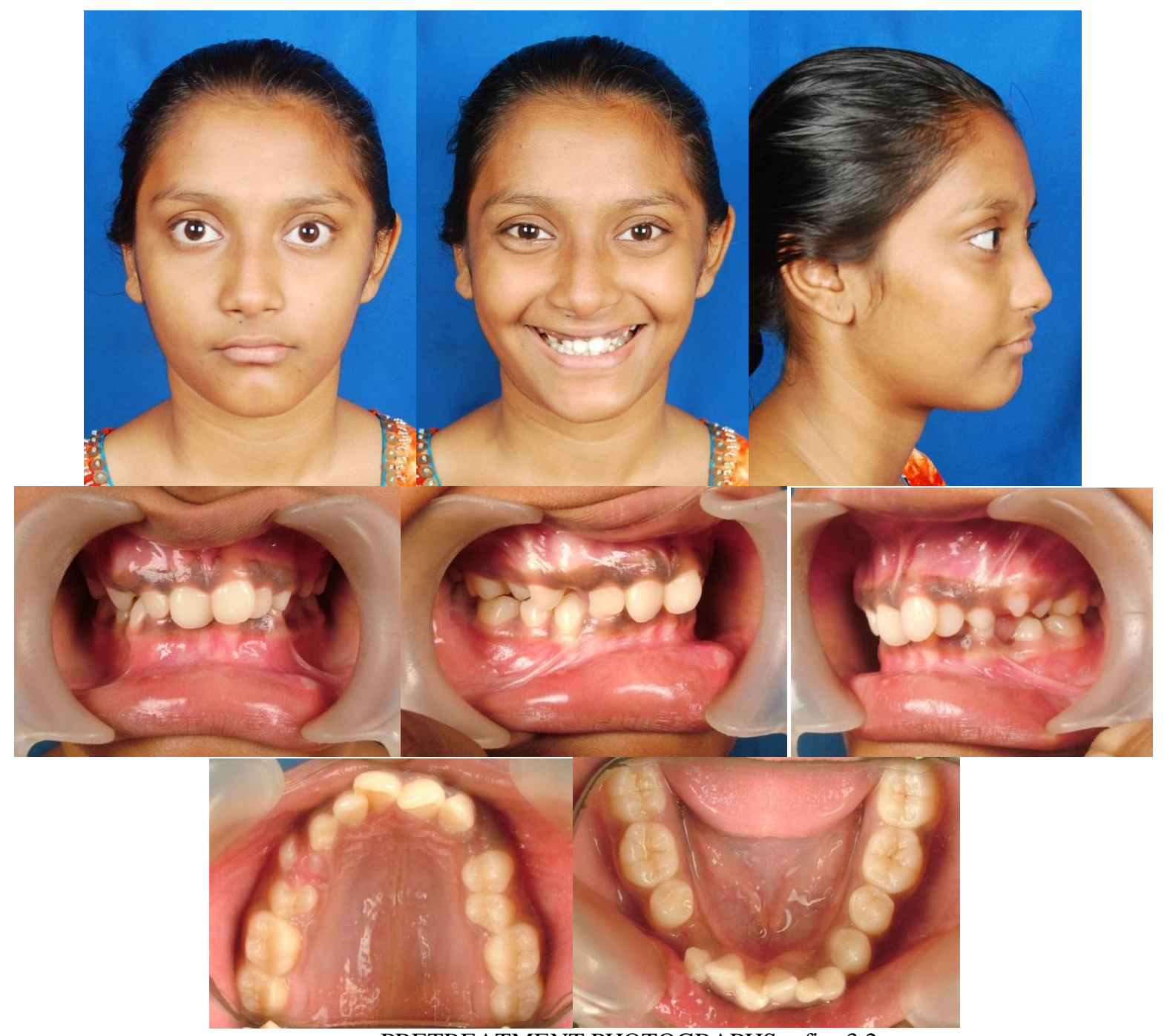

PRETREATMENT PHOTOGRAPHS - fig. 3.2

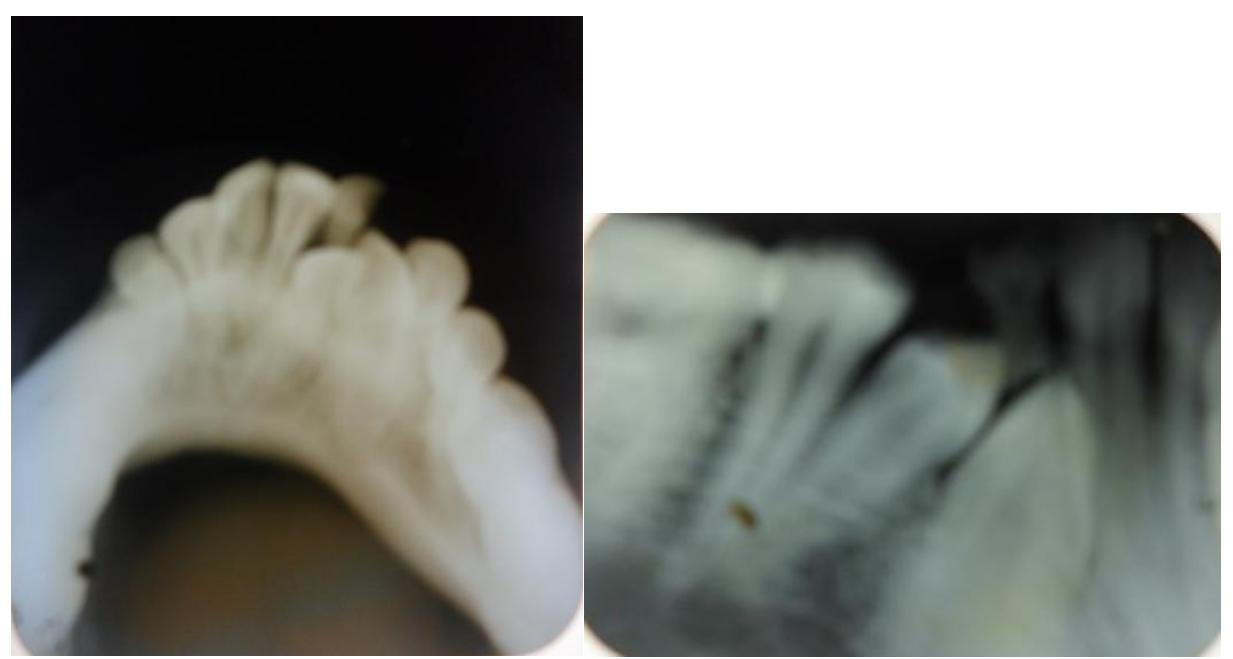

BEFORE EXTRACTION OF LOWER LEFT CANINE 


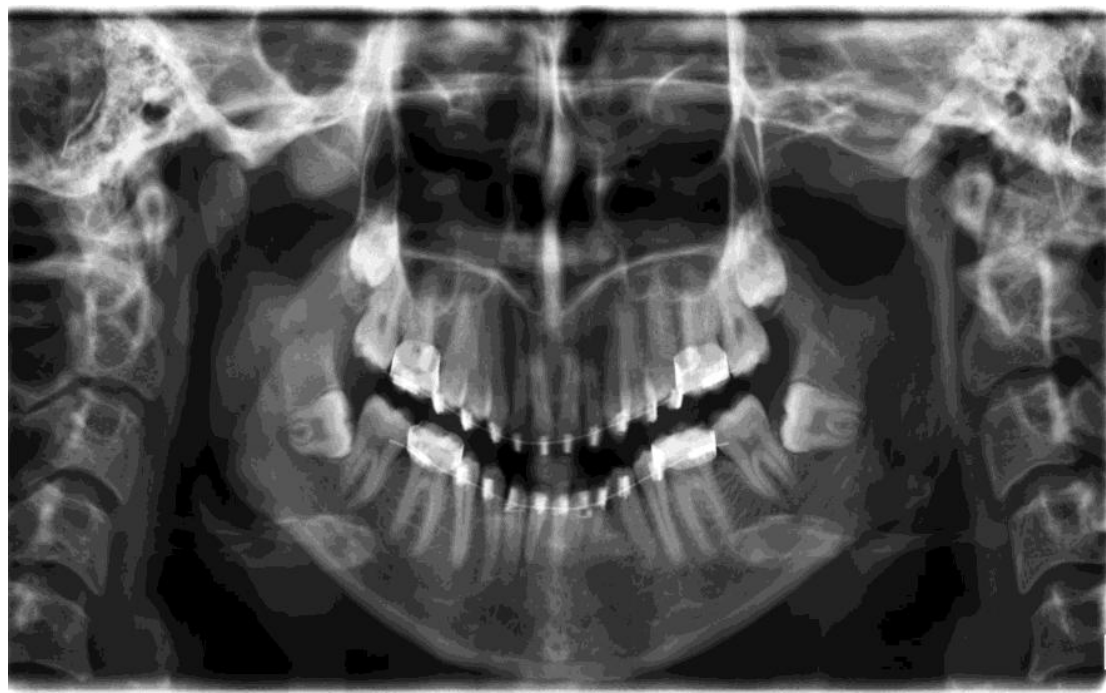

AFTER ORTHODONTIC TRACTION OPG - fig. 3.1.1

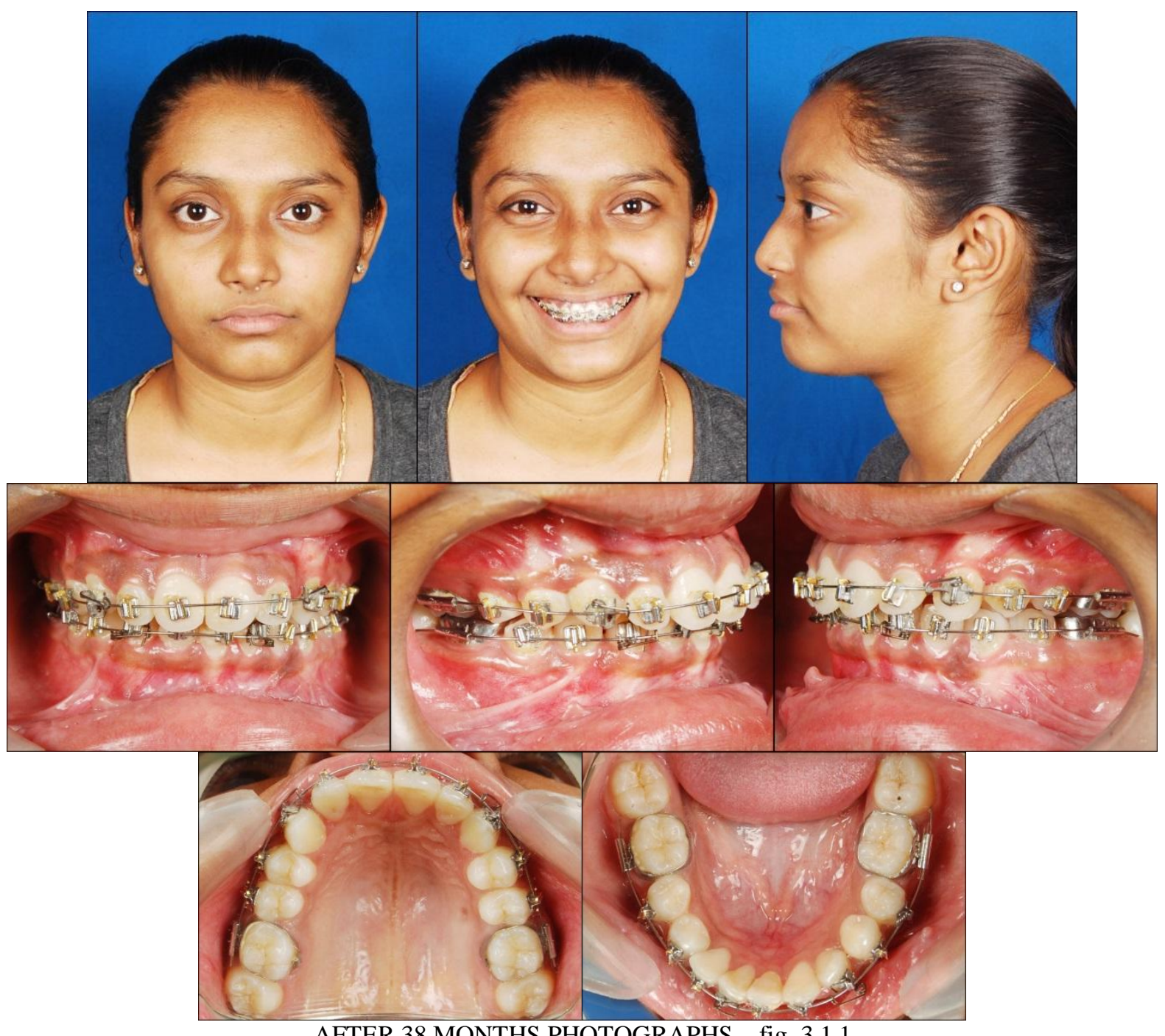


- CASE 4: 'Unilateral left impacted canine with opposite canine in buccal occlusion'

A female 13 years old patient reported with the chief complain of spacing in upper teeth. On examination the findings revealed angle's class I malocclusion with average growth pattern, impacted left maxillary canine, bucally placed right maxillary canine, spacing distal to maxillary lateral incisor on both sides, convex soft tissue profile, acute nasolabial angle, proclined and bodily forwardly placed upper and lower anteriors .(fig. 4.1)

Treatment plan was decided to extract all (first premolars)

and both maxillary canine aligned to the dental arch form .

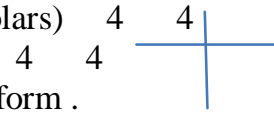

Surgical exposure of impacted left maxillary canine was done by tunnel traction techniqueandbegg's bracket bonded on labial surface, ligated with 0.009 ligature wire to 0.016 round NiTi.

Upper 0.016 special base arch wire with intermaxillary circle on distal surface of both lateral incisor with occlusobuccal offset from distal of circle to distal surface of rightcanine bracket. High hat pin is pinned up on right canine and short span E-chain elastic force is given from canine bracket to intermaxillary circle along with light class II elastics $(1.5 \mathrm{oz})$ on both the sides. 2112 was consolidated with 0.009 ligature wire.

Simultaneous orthodontic forced eruption of left maxillary canine with mesialisaition of both the canines was continued with moderate retraction of incisors, by utilizing extraction space of first premolar. After active treatment of 18 months, both the maxillary canines were brought to class I occlusion and provide pleasant smile.(fig. 4.1.2)

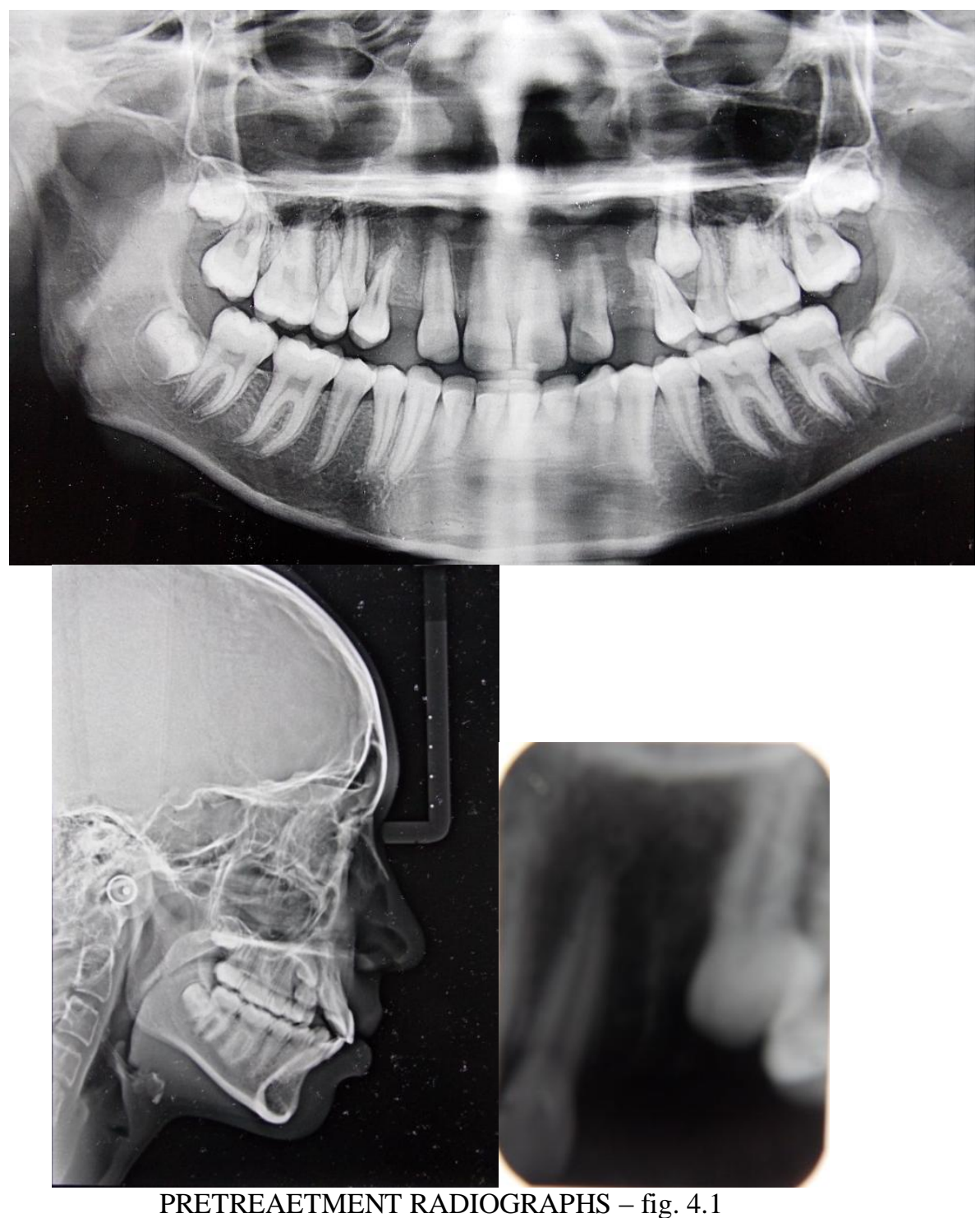




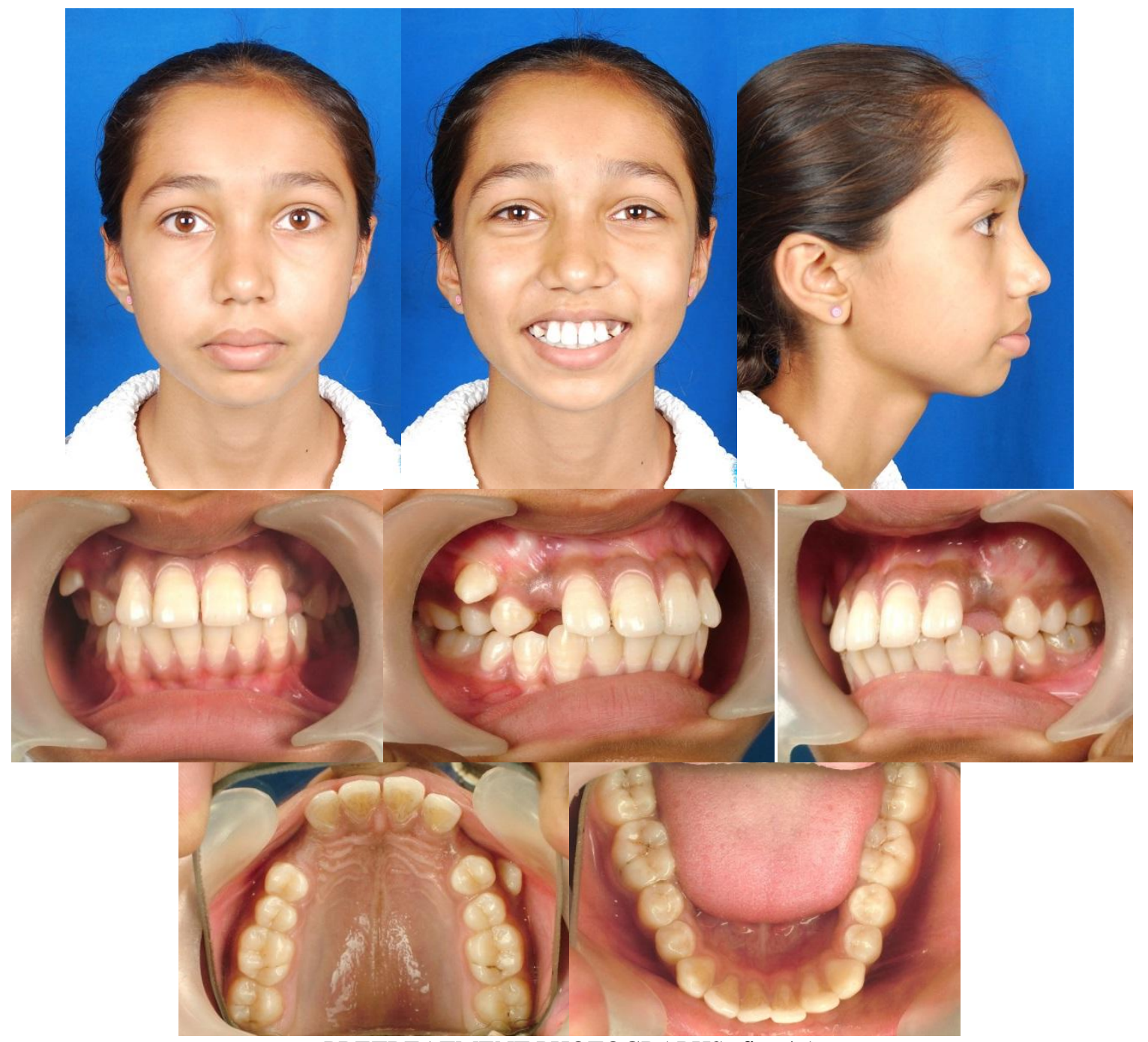

PRETREATMENT PHOTOGRAPHS- fig. 4.1

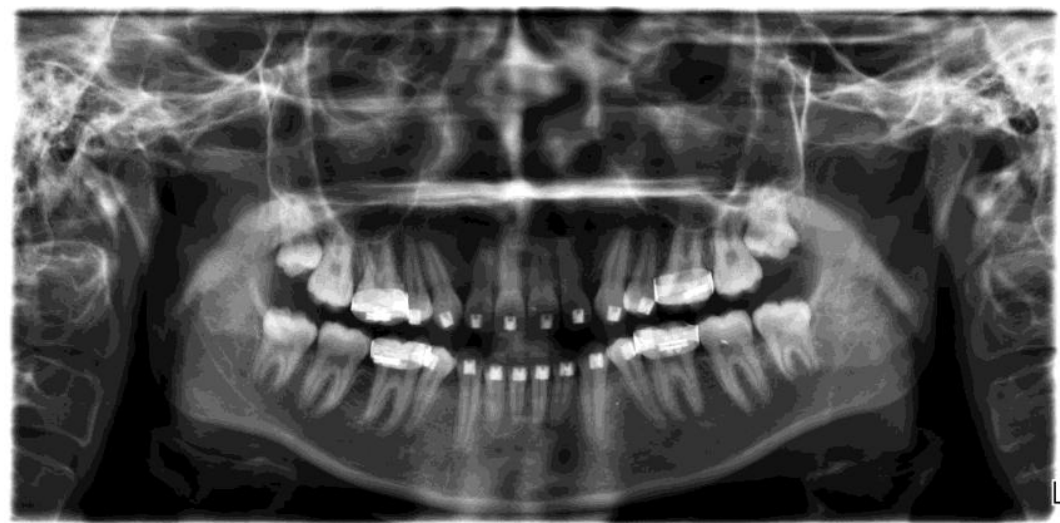




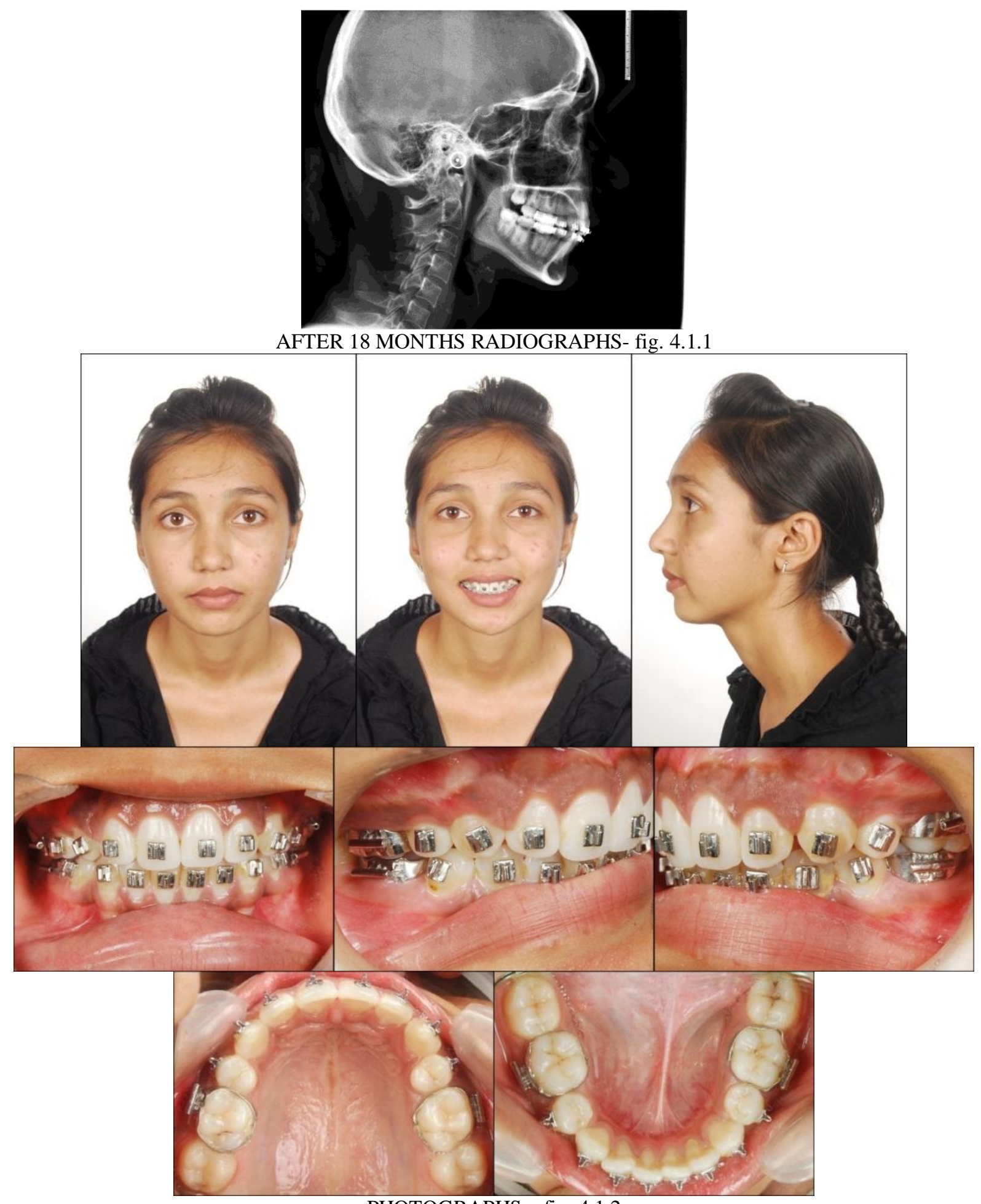

PHOTOGRAPHS - fig. 4.1.2

- $\quad$ Case 5: Unilateral left impacted first premolar with over retained deciduous molar and supplemental tooth.

A male 16 years old patient reported with chief complain of irregularly arranged teeth and difficulty in biting. On examination findings revealed overretained left deciduous first molar, horizontally impaced lower left first premolar, crossbite in upper right central incisor, bucally placed left canine, supernumerary tooth between upper left lateral incisor and canine, Angle's class-I malocclusion with horizontal growth pattern.(fig. 5.1)

Treatment was started with extraction of supernumerary tooth and lower deciduous first molar followed by alignment of upper arch with piggy back technique ( 0.016 base arch wire with high hat pin on left canine and $0.016 \mathrm{NiTi}$ ) and lower removable posterior bite plate. 
After nine months of active treatment extraction of lower left impacted first premolar was planned due to unfavourable position along with upper first premolar extraction space is utilized for reliving crowding, leveling and midline correction. After 28 months class I occlusion with pleasant smile and profile is achieved.(fig. 5.1.1)
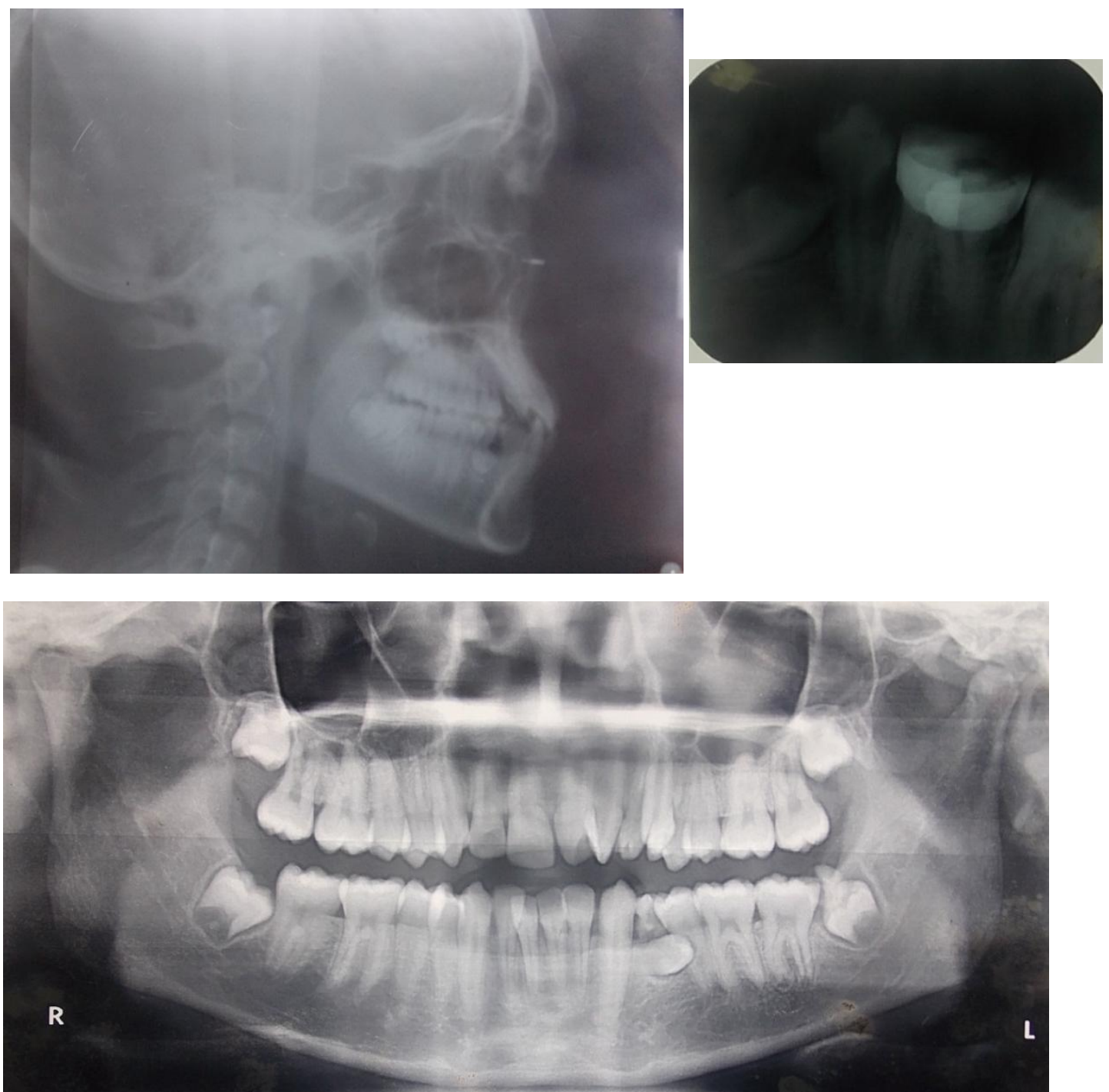

PRETREATMENT RADIOGRAPH - fig. 5.1

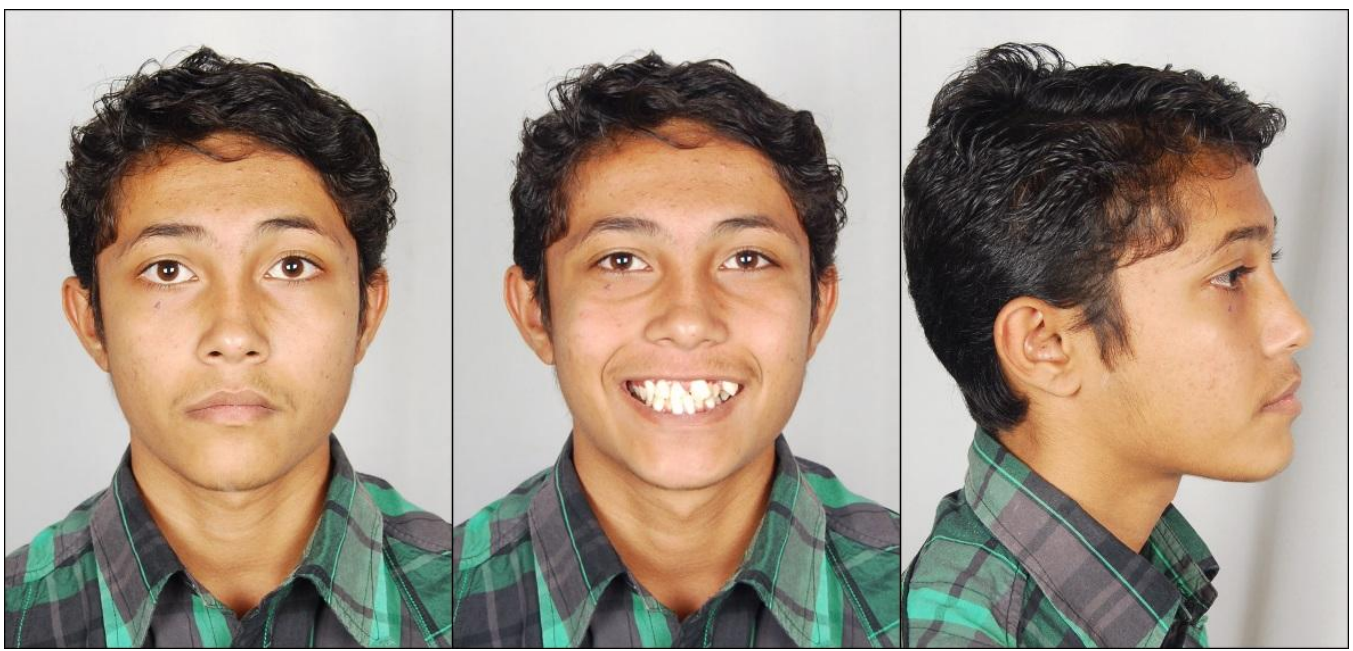

www.iosrjournals.org 


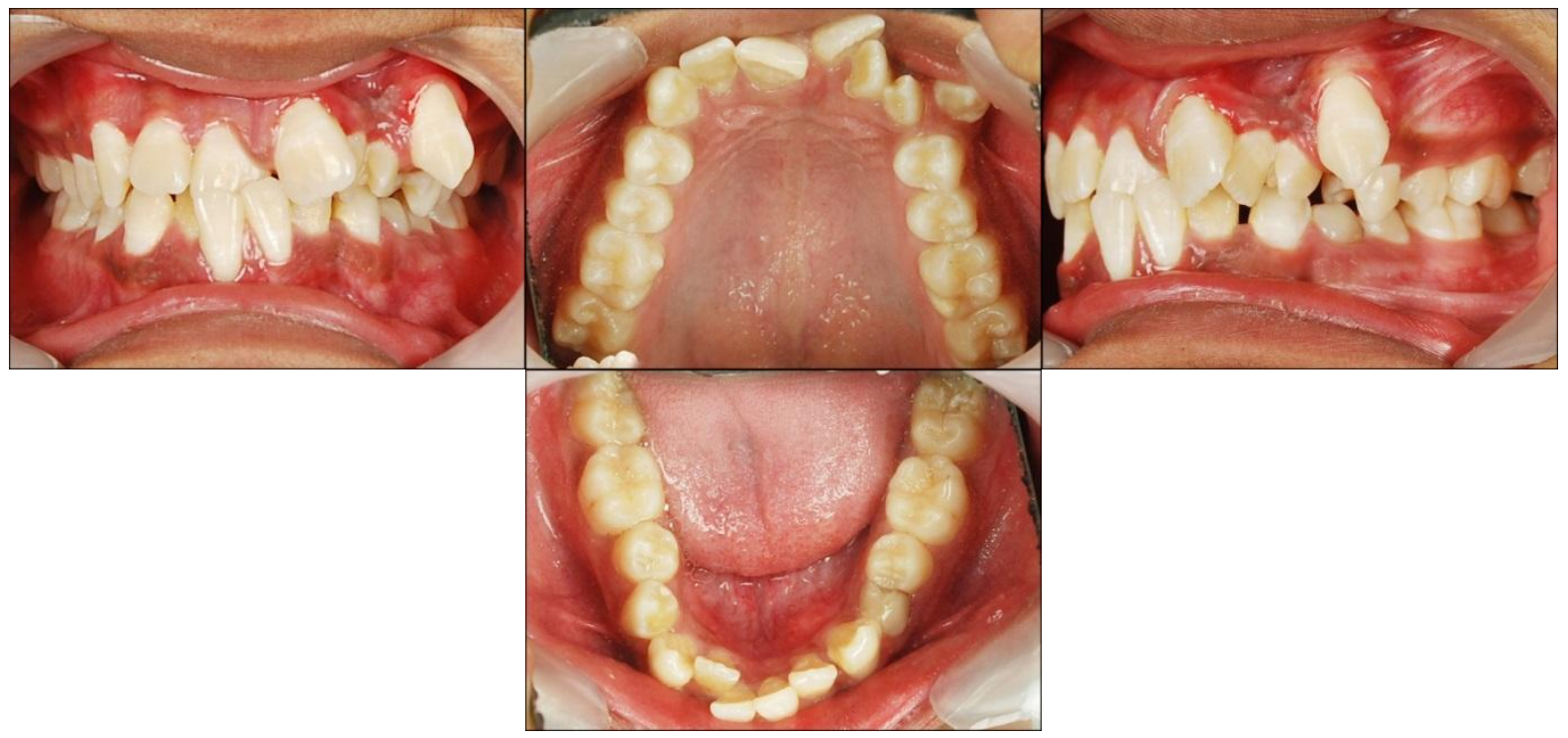

PRETREATMENT PHOTOGRAPHS - fig. 5.1

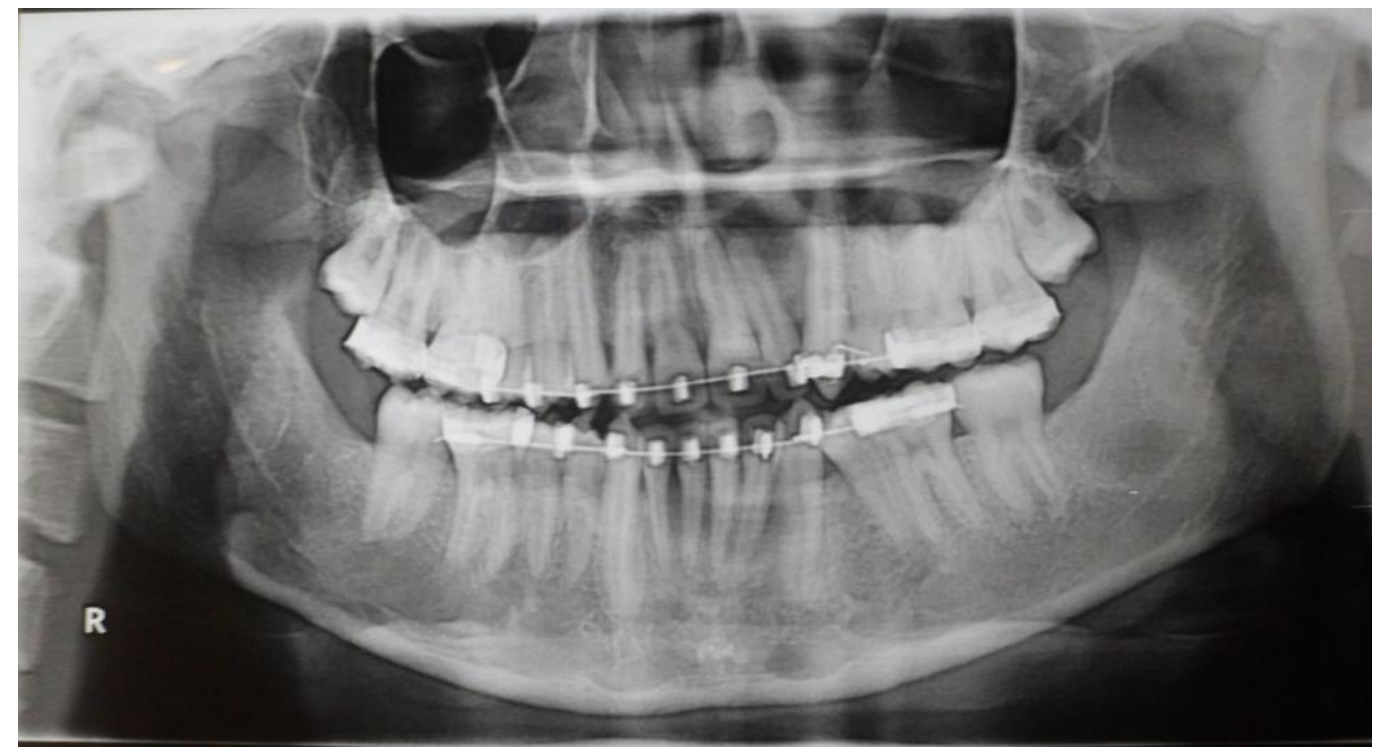

AFTER 28 MONTHS OF ORTHODONTIC TREATMENT-OPG

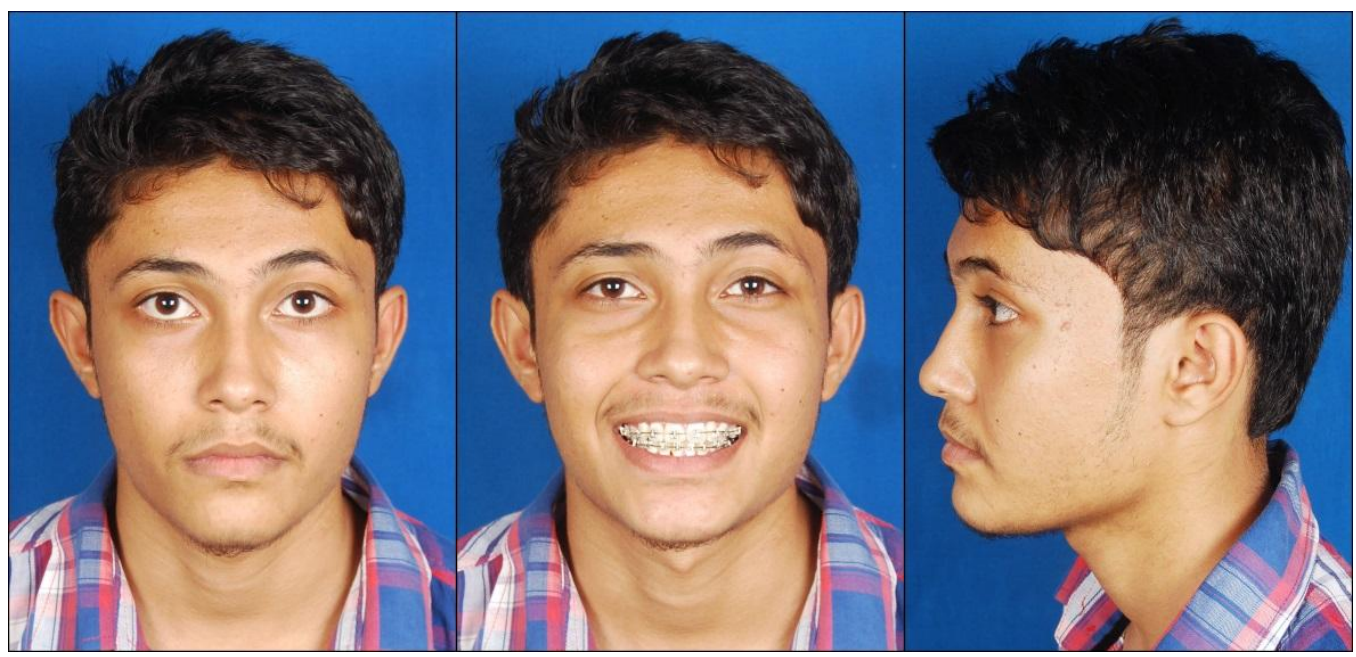




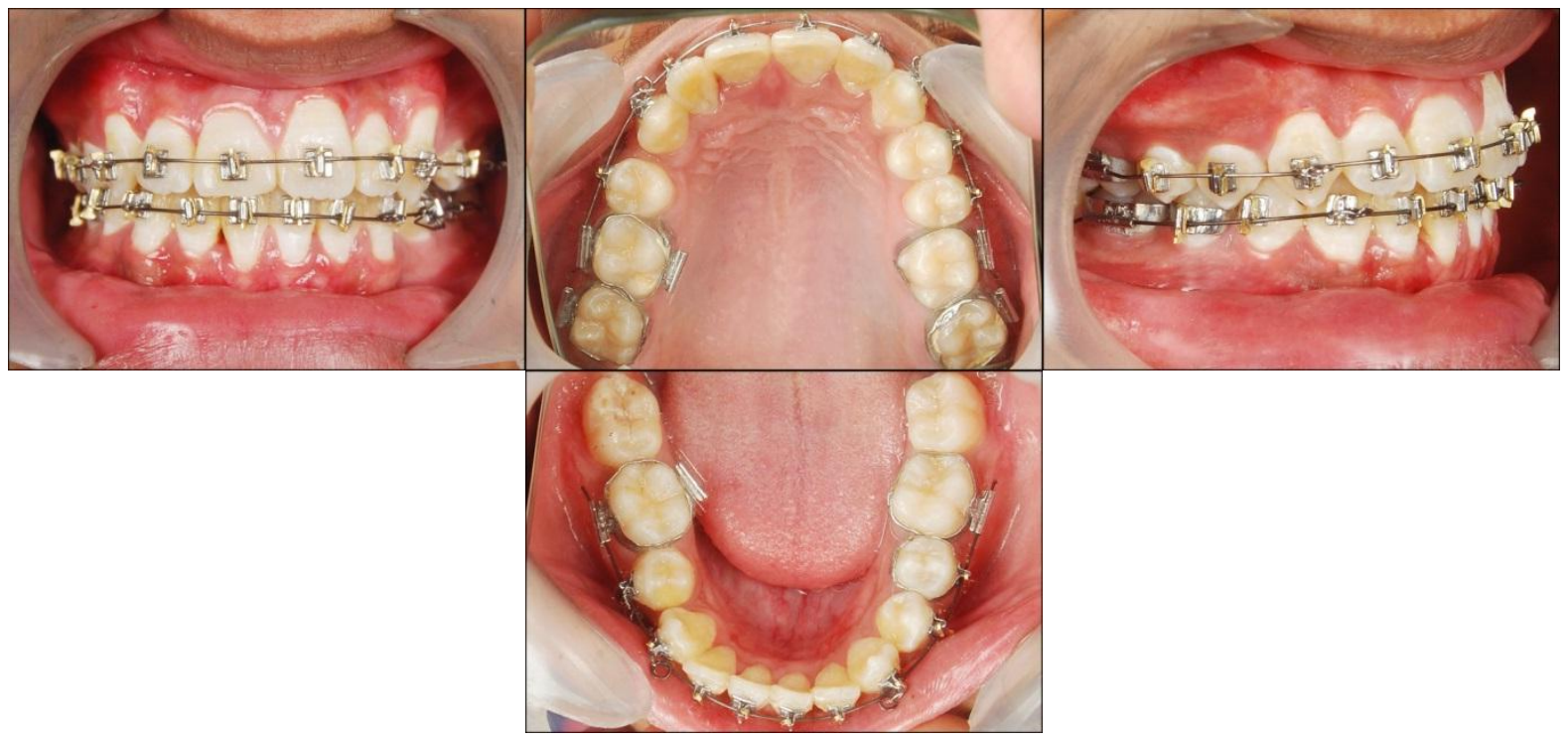

AFTER 28 MONTHS PHOTOGRAPHS - fig. 5.1.1

\section{Conclusion}

Thus management of the impacted teeth is one of the greatest challenge for orthodontist.It is recommended that the decision regarding orthodontic forced eruption (closed or open), or extraction bebased on evaluation of each independent case.Ankylosis, resorption,eruption failure, periodontalpockets, bondingfailure, are complicationsthat need to be taken into account.

Success of the treatment depends upon cooperation and Age of the patient, Proper diagnosis, Level of impaction, Inclination and Depth of impaction, Amount of root formation, Type of exposure of tooth, Amount of bone removal, Type of attachment, Orthodontic traction. All these parameters play an important role when managing impacted teeth to achieve good alignment in the arch, gingival level, and integrity of periodontium. Finally, the more precise the location and position of the impacted tooth is known, the easier the procedure becomes.

Orthodontic treatment can be very rewarding if we are ready to accept the challenge of anticipating the changes, on the basis of a sound problem list and treatment goals.

\section{Acknowledgement}

We are thankful to oral surgery department,GDCH Ahmedabad..

\section{References}

[1]. Orthodontic treatment of impacted teeth - Ardian Becker.

[2]. AJO 1983, Aug ,125 - 132 The etiology of maxillary canine impactions - Jacoby.

[3]. AJO 1994 ,Jan ,61 - 72 Tunnel traction of infraosseous impacted maxillary canines - Crescini, Clauser, Giorgetti, Cortellini, and Prato.

[4]. AJO,1982 Mar ,236 - 239 Txt Orthodontic considerations in the treatment of maxillary impacted canines - Fournier, Turcotte, and Bernard.

[5]. AJO1991, Dec ,494 - 512 Txt Rare earth magnets and impaction - Vardimon, Graber, Drescher, and Bourauel.

[6]. Seminar in orthodontics, vol 16 no 3 sept2010,p 163 - 142 - management of impacted teeth. 